\title{
Antitumor effect of Melaleuca alternifolia essential oil and its main component terpinen-4-ol in combination with target therapy in melanoma models
}

\author{
Marta Di Martile $\mathbb{D}^{1}$, Stefania Garzoli ${ }^{2}$, Manuela Sabatino ${ }^{2,3}$, Elisabetta Valentini ${ }^{1}$, Simona D'Aguanno ${ }^{1}$, \\ Rino Ragno ${ }^{2,3}$ and Donatella Del Bufalo (1) ${ }^{1}$
}

\begin{abstract}
Essential oils (EOs) have been recently emerging for their promising biological activities in preventing tumorigenesis or progression of different tumor histotypes, including melanoma. In this study, we investigated the antitumor activity of a panel of EOs in different tumor models. The ability of Melaleuca alternifolia (tea tree oil) and its main component, terpinen-4-ol, to sensitize the target therapy currently used for melanoma treatment was also assessed. Our results demonstrated that EOs differently affect the viability of human cancer cells and led us to select six EOs effective in melanoma and lung cancer cells, without toxic effects in human fibroblasts. When combined with dabrafenib and/or trametinib, Melaleuca alternifolia synergistically reduced the viability of melanoma cells by activating apoptosis. Through machine learning classification modeling, a-terpineol, tepinolene, and terpinen-4-ol, three components of Melaleuca alternifolia, were identified as the most likely relevant components responsible for the EO's antitumor effect. Among them, terpinen-4-ol was recognized as the Melaleuca alternifolia component responsible for its antitumor and proapoptotic activity. Overall, our study holds promise for further analysis of EOs as new anticancer agents and supports the rationale for their use to improve target therapy response in melanoma.
\end{abstract}

\section{Introduction}

Cutaneous melanoma is the most aggressive type of skin cancer. BRAF represents the most common driver mutation present in $\sim 50 \%$ of patients and predicting a more aggressive behavior ${ }^{1}$. Although target therapy and immunotherapy represent a great opportunity for melanoma treatment, patients often face lack of clinical response, the emergence of resistance to treatment, and invalidating side effects ${ }^{2}$. Consequently, innovative and

\footnotetext{
Correspondence: Marta Di Martile (marta.dimartile@ifo.gov.it) or

Rino Ragno (rino.ragno@uniroma1.it)

${ }^{1}$ Preclinical Models and New Therapeutic Agents Unit, IRCCS Regina Elena

National Cancer Institute, Via Elio Chianesi 53, Rome, Italy

${ }^{2}$ Rome Center for Molecular Design, Department of Drug Chemistry and

Technology, Sapienza University, Piazzale Aldo Moro 5, Rome, Italy

Full list of author information is available at the end of the article

Edited by Ivano Amelio
}

combined therapies are still urgent to treat and eventually eradicate advanced melanoma. In light of this consideration, a large number of preclinical and clinical trials are ongoing to identify new therapeutic approaches.

Over the past decades, compounds extracted from plants have demonstrated their effectiveness in different diseases, including melanoma ${ }^{3}$. Examples include vinblastine ${ }^{4}$, vincristine $^{5}$, paclitaxel $^{6}$, and camptothecin ${ }^{7}$. Scientific evidences have demonstrated that, among natural compounds, essential oils (EOs) showed great potential for the management of a number of diseases including cardiovascular $^{8}$, diabetes ${ }^{9}$, and Alzheimer ${ }^{10}$. EOs also represent a valid source to prevent the invasion of SARS-CoV-2 into the human body ${ }^{11}$, or to downregulate angiotensinconverting enzyme 2 expression in epithelial cells ${ }^{12}$.

\section{(c) The Author(s) 2021}

(c) (i) Open Access This article is licensed under a Creative Commons Attribution 4.0 International License, which permits use, sharing, adaptation, distribution and reproduction cc) in any medium or format, as long as you give appropriate credit to the original author(s) and the source, provide a link to the Creative Commons license, and indicate if changes were made. The images or other third party material in this article are included in the article's Creative Commons license, unless indicated otherwise in a credit line to the material. If material is not included in the article's Creative Commons license and your intended use is not permitted by statutory regulation or exceeds the permitted use, you will need to obtain permission directly from the copyright holder. To view a copy of this license, visit http://creativecommons.org/licenses/by/4.0/. 
Due to their minimal cytotoxicity ${ }^{13,14}$, EOs are considered pharmaceutically safe and could represent a good alternative natural source of anticancer agents, thus deserving further investigations to ascertain their mechanism of action and to validate their possible clinical uses as alternative/complementary antitumor agents. In the last 20 years, preclinical studies demonstrated anticancer activity of either some EOs or their main components ${ }^{15,16}$ and led to case-control studies $^{17}$ and clinical trials ${ }^{18-20}$. At present, EOs are used to ameliorate cancer patients' quality of life and clinical trials are ongoing to evaluate their efficacy or the efficacy of their components in cancer patients (NCT02336087, NCT03449 303, NCT04560114, NCT04449315, NCT00003219, NCT00 003238, NCT01459172, NCT01046929, NCT04296266). From the hundreds of studies published in the last years, it is evident that, in addition to their chemopreventive effects, several EOs and their constituents show antioxidant, antiproliferative, proapoptotic, antiangiogenic, and antimetastatic activity in melanoma models ${ }^{21-23}$. Synergistic effect of EO components such as geraniol ${ }^{24,25}, \beta$-elemene ${ }^{26,27}$, $\beta$-caryophyllene ${ }^{28}$, limonene ${ }^{29}$, eugenol ${ }^{30}$, and thymoquinone ${ }^{31,32}$ with cancer therapy has been also reported.

To shed light on the use of EOs as possible anticancer agents, in this investigation we reported the in vitro anticancer effect of a panel of EOs and investigated the possible use of Melaleuca alternifolia (TTO, EO05 in this investigation) as a sensitizer of targeted therapy in melanoma models. Furthermore, machine learning (ML) classification models were developed and used to investigate the possible efficacy of the more important EOs' single components.

\section{Results}

A panel of EOs differently affects the viability of melanoma cells

The antitumor activity of 61 EOs (Table S1) was firstly assessed for their ability to affect the proliferation/viability of M14 melanoma cell line $(50 \mu \mathrm{g} / \mathrm{ml}, 72 \mathrm{~h})$. As reported in Fig. 1a, 18 EOs significantly reduced the proliferation/ viability of M14 cells, and 12 of them inhibited at least $50 \%$ of cell proliferation. Among the 12 EOs, EO14 and EO40 were excluded from further investigations owing to their low solubility. M14 cells were treated with the remaining 10 EOs $(10-50 \mu \mathrm{g} / \mathrm{ml}, 24-72 \mathrm{~h})$. After $24 \mathrm{~h}$ treatment, a dose-dependent reduction of cell proliferation/viability was observed for seven EOs, whereas between $48 \mathrm{~h}$ and $72 \mathrm{~h}$ no significant differences in terms of $\mathrm{IC}_{50}$ were observed (Fig. 1b, c, Table S2). EO22, EO32, and EO52 were the less effective in reducing the M14 proliferation/viability and showing the highest deviation from the median $\mathrm{IC}_{50}$ for each time point (Fig. 1b, c).

As reported in Fig. S1a, the six most effective EOs (EO05, EO12, EO18, EO20, EO29, EO49), but not EO39, showed no significant effect on the proliferation/viability of normal human fibroblasts $(50 \mu \mathrm{g} / \mathrm{ml}, 72 \mathrm{~h})$, therefore EO39 was not further investigated. The antitumor activity of the final selected EOs was then explored on cell lines with three different tumor histotypes: lung (H1299, A549), colon (HCT116), and breast (MDA-MB-231) carcinoma. As shown in Fig. S1b, lung cancer cells treated with each EO $(50 \mu \mathrm{g} / \mathrm{ml}, 48 \mathrm{~h})$ were as sensitive as M14 cells, with cell proliferation/viability inhibition ranging from $67 \%$ to $82 \%$ for both cell lines used. On the contrary, the proliferation/viability of MDA-MB-231 cells was significantly reduced only by EO12, whereas HCT116 cells were resistant to the six EOs.

Even though at different extend, increasing concentrations of each EO displayed a similar ability in significantly reducing the viability of both BRAF wild type/NRAS mutant (Sbcl1, ME4405), BRAF wild type NRAS wild type (ME1007), and BRAF mutant/NRAS wild type (M14, A375, LOX IMVI) melanoma cells (Fig. 2a-f, Fig. S1c), thus indicating the absence of relevance of BRAF or NRAS status in the sensitivity to EOs.

\section{ML binary classification algorithms identify the most likely relevant components of EOs}

To identify the most important chemical components likely responsible for viability inhibition of M14 cells, ML models were developed as reported in supplementary methods. At $50 \%$ proliferation/viability inhibition threshold, Matthews correlation coefficient and area under the curve value were 0.604 and 0.537 , respectively (Fig. S2a). Inspection of the weighted feature importance values revealed $\alpha$-terpineol, terpinolene, and terpinen-4-ol as those components mainly responsible for proliferation/ viability inhibition of M14 cell line (Fig. S2a). The chemical composition of the EOs with the higher efficacy is reported in Table 1 and Tables S4-S8. All the three components identified through ML analysis were evidenced only in EO05 and EO49, even if at different concentrations (Table S3).

\section{EO05 sensitizes melanoma cells to target therapy}

We next combined EO05, a very well characterized EO from Melaleuca alternifolia ${ }^{33}$ containing all the three components identified through the ML approach, with the targeted therapy currently used for the treatment of advanced melanoma patients harboring BRAF mutations $^{34}$. Growth inhibitory curve and relative analysis of drug interaction demonstrated that $24 \mathrm{~h}$ EO05 followed by $48 \mathrm{~h}$ dabrafenib (BRAF inhibitor) resulted in a synergistic effect on M14 proliferation/viability reduction with combination index $(\mathrm{CI})=0.6$ (Fig. 3a). Accordingly, this combination produced a synergistic effect also in A375 cells (Fig. S3a).

A mean of $18.5 \%$ and $16.8 \%$ of subG1 peak, indicative of dead cells, was detected after treatment with dabrafenib or 


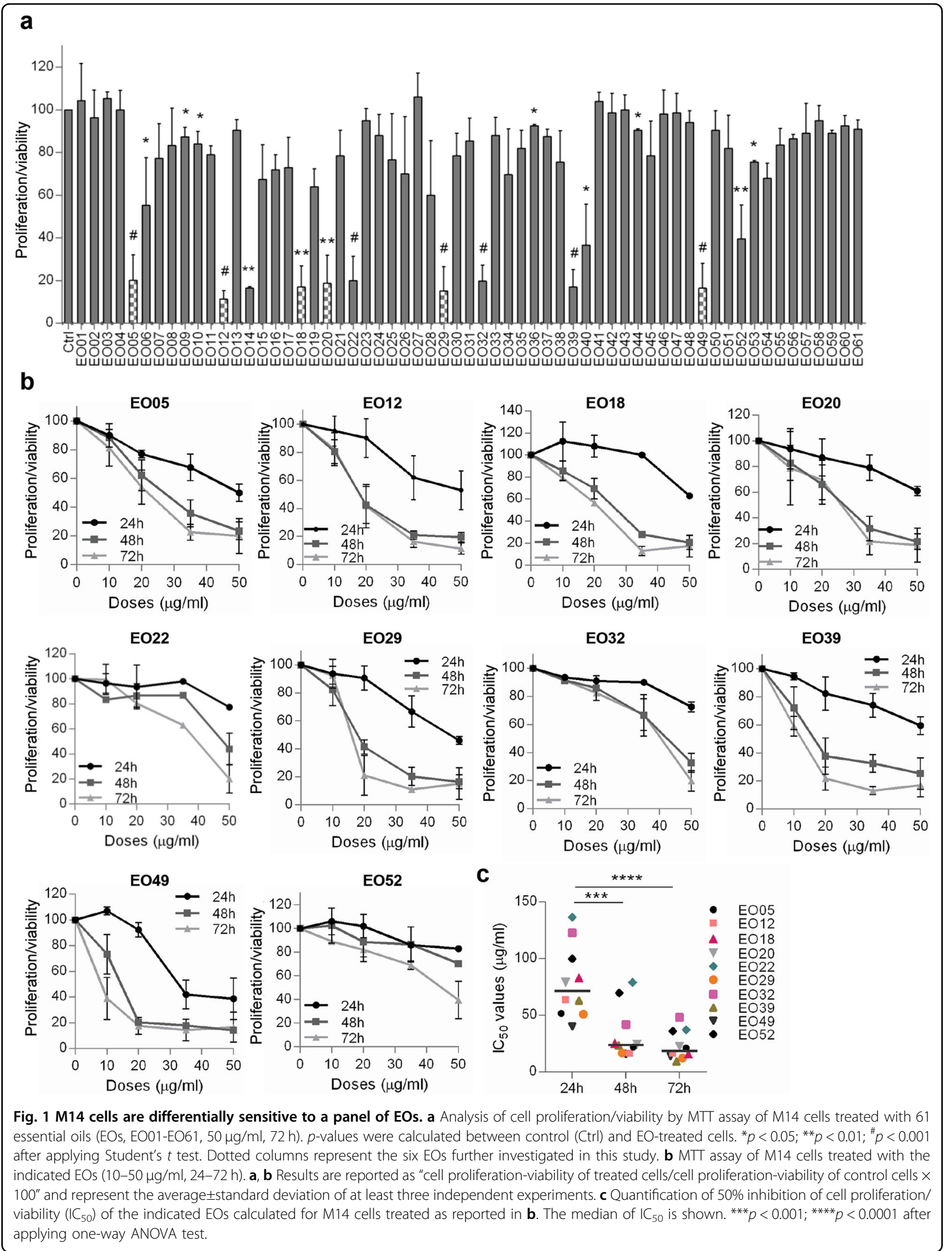


a

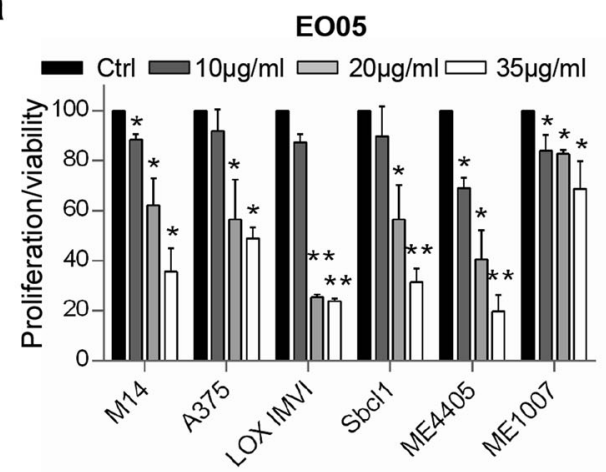

C

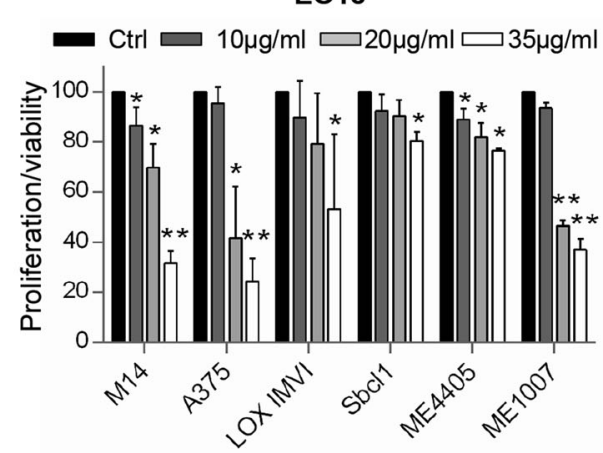

e

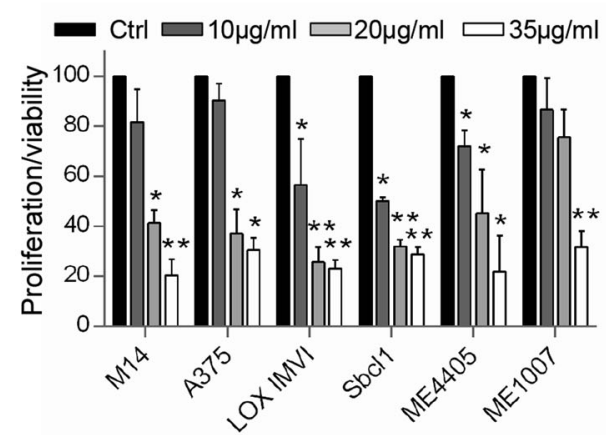

b

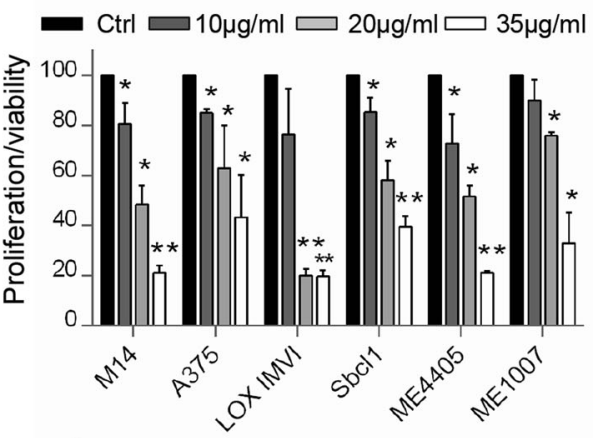

d

EO20

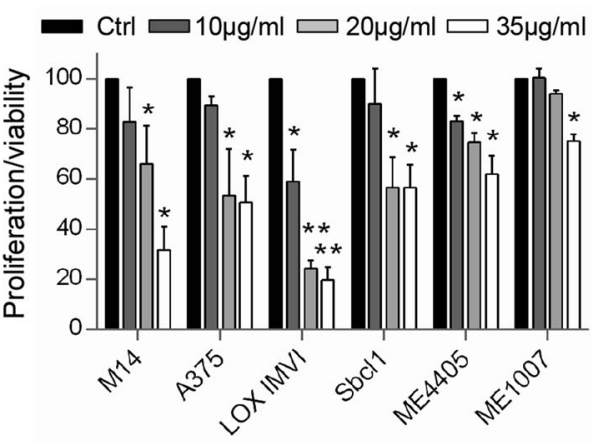

f

EO49

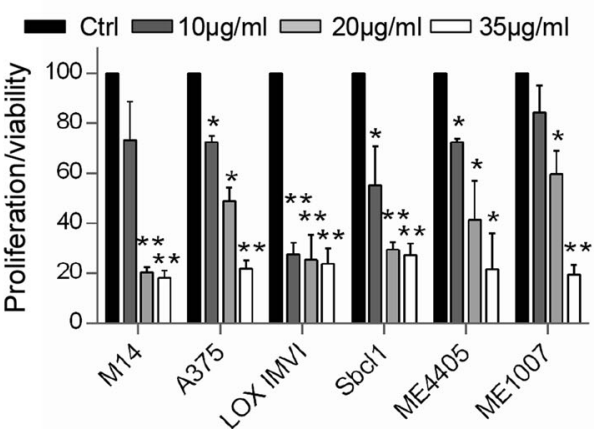

Fig. 2 Six selected EOs affect melanoma cell proliferation/viability. a-f Analysis of cell viability by MTT assay of six melanoma cell lines treated with the indicated EOs $(10-35 \mu \mathrm{g} / \mathrm{ml}, 48 \mathrm{~h})$. The results are reported as "cell proliferation-viability of treated cells/cell proliferation-viability of control cells $(\mathrm{Ctrl}) \times 100^{\prime \prime}$ and represent the average \pm standard deviation of at least three independent experiments. $p$-values were calculated between control and EOs treated cells. ${ }^{*} p<0.05 ;{ }^{* *} p<0.01$ after applying Student's $t$ test.

EO05, respectively. Interestingly, in cells treated with EO05 followed by dabrafenib, the subG1 population significantly increased up to $40.2 \%$ (Fig. 3b, c). In addition, treatment with the caspase inhibitor zVAD-FMK (zVAD) significantly reduced the subG1 peak in cells treated with EO05 alone (4.9\%) or in combination with dabrafenib (8\%), thus demonstrating apoptotic cell death. Apoptosis induction was also confirmed by the increase of active caspase 3 and cleaved PARP in cells treated with the combination when compared to single treatments (Fig. 3d, e).
Similar to what observed for dabrafenib, administration of $24 \mathrm{~h}$ EO05 followed by $48 \mathrm{~h}$ trametinib (MEK inhibitor) showed a synergistic effect strongly reducing M14 cell proliferation/viability $(\mathrm{CI}=0.5)$ (Fig. 4a). Accordingly, treatment of EO05 followed by trametinib increased the percentage of subG1 peak, caspase 3, and PARP cleavage (Fig. 4b-e) when compared with trametinib or EO05 alone. Moreover, the addition of zVAD significantly decreased the subG1 peak in cells treated with EO05 alone or in combination (Fig. 4b, c). A synergistic effect of 
Table 1 Chemical composition of EO05.

\begin{tabular}{|c|c|c|c|c|}
\hline No. & Component $^{\mathrm{a}}$ & $\operatorname{LRI}^{\mathbf{b}}$ & $\mathrm{LRI}^{\mathrm{c}}$ & EO05 (\%) ${ }^{d}$ \\
\hline 1 & a-pinene & 1019 & 1021 & 11.1 \\
\hline 2 & $\beta$-pinene & 1100 & 1105 & 2.5 \\
\hline 3 & $\beta$-myrcene & 1157 & 1157 & 0.2 \\
\hline 4 & a-terpinene & 1180 & 1186 & 4.6 \\
\hline 5 & Limonene & 1195 & 1198 & 2.0 \\
\hline 6 & Eucalyptol & 1201 & 1209 & 14.9 \\
\hline 7 & y-terpinene & 1236 & 1241 & 11.8 \\
\hline 8 & Terpinolene & 1281 & 1282 & 1.7 \\
\hline 9 & o-cymene & 1283 & 1287 & 3.5 \\
\hline 10 & Linalool oxide & 1420 & 1423 & 0.2 \\
\hline 11 & a-gurjunene & 1529 & 1527 & 0.2 \\
\hline 12 & Longifolene & 1579 & 1583 & 0.2 \\
\hline 13 & Terpinen-4-ol & 1599 & 1603 & 37.5 \\
\hline 14 & a-terpineol & 1677 & 1675 & 8.1 \\
\hline 15 & Viridiflorene & 1699 & 1695 & 1.1 \\
\hline \multirow[t]{2}{*}{16} & Globulol & 2092 & 2086 & 0.4 \\
\hline & Total identified & & & 100.0 \\
\hline
\end{tabular}

The chemical composition of EO05 was identified by GC-MS analysis.

${ }^{\text {aT }}$ The components are reported according to their elution order on polar column.

binear Retention indices (LRI) measured on polar column.

'LRI from literature.

${ }^{\mathrm{d} P e r c e n t a g e}$ mean values of EO05 components.

EO05 followed by trametinib was also obtained in the BRAF wild type melanoma cells, ME4405 $(\mathrm{CI}=0.6)$ (Fig. S3b). Next, the effect of EO05 in combination with dabrafenib and trametinib, the current standard treatment for BRAF mutant melanoma patients, was also assessed. Interestingly, $24 \mathrm{~h}$ EO05 followed by $48 \mathrm{~h}$ of dabrafenib/ trametinib treatment strongly reduced the proliferation/ viability of M14 cells compared with exposure to EO05 alone or to dabrafenib/trametinib (Fig. 4f).

\section{Terpinen-4-ol is responsible for EO05 antitumor activity}

Four among the most abundant components of EO05, identified by gas chromatography mass spectroscopy (GC/ MS) analysis (Table 1) were tested for their ability to affect M14 and A375 cell proliferation/viability at the concentration contained in $50 \mu \mathrm{g} / \mathrm{ml}$ of EO05. Terpinen-4-ol $(18.5 \mu \mathrm{g} / \mathrm{ml}, 48 \mathrm{~h})$, was the only component that significantly reduced M14 (Fig. 5a) and A375 (Fig. S4a) proliferation/viability of $\sim 70 \%$ and $60 \%$, respectively, an effect similiar to that exerted by EO05 at $50 \mu \mathrm{g} / \mathrm{ml}$. On the contrary, eucalyptol $(7 \mu \mathrm{g} / \mathrm{ml}), \gamma$-terpinene $(6 \mu \mathrm{g} / \mathrm{ml})$, and $\alpha$-terpineol $(4 \mu \mathrm{g} / \mathrm{ml})$ had no significant effect on M14 and A375 cell proliferation/viability (Fig. 5a, Fig. S4a).
Furthermore, treatment with terpinen-4-ol for $48 \mathrm{~h}$ significantly decreased M14 (Fig. 5b) and A375 (Fig. S4b) cell proliferation/viability in a dose-dependent manner, up to $64 \%$ and 56\%, respectively, likewise EO05 (64.3\% for M14 and $51 \%$ for A375, respectively).

Interestingly, as determined for EO05, terpinen-4-ol pre-treatment synergistically reduced cell viability of M14 cell line when associated with dabrafenib $(\mathrm{CI}=0.44)$ (Fig. 5c) or trametinib ( $\mathrm{CI}=0.7)$ (Fig. 5d). Accordingly, an increased subG1 peak, reduced by the addition of zVAD, was observed in cells treated with combinations with respect to single treatments (Fig. 6a, b). The apoptotic induction of the combinations was confirmed by the increase of PARP and caspase 3 cleavage (Fig. 6c, d). Analogous results were obtained for A375 when terpinen4-ol was followed by dabrafenib $(\mathrm{CI}=0.5)$ or trametinib $(\mathrm{CI}=0.47)$ (Fig. S4c, d). Interestingly, the terpinen-4-ol pre-treatment strongly synergized the effect of dabrafenib/trametinib treatment (Fig. 6e).

\section{Discussion}

In this study, we provided evidence about the antiproliferative effect of a panel of EOs in melanoma and lung carcinoma cells. More importantly, we determined the ability of TTO to synergize with target therapy in melanoma models. In particular, an initial screening of 61 EOs led to select six of them (TTO, Pinus Sylvestris, Lavandula Angustifolia, Citrus Paradisi, Pinus Sibirica, Cupressus Sempervirens) as the most efficacious in terms of reduction of tumor cell proliferation/viability, without affecting normal fibroblasts viability. We also found that the efficacy of EOs depends on the tumor histotype examined. In fact, the treatment with the six EOs reduced cell proliferation of melanoma and lung carcinoma cells in a dose-dependent manner, whereas they were ineffective in breast and colon carcinoma cells. The mechanism that renders the different histotypes differently sensitive to the six EOs is not yet clear. No reports have been yet published about the six EOs used in colon cancer models. Nevertheless, TTO has been reported to induce apoptosis in breast cancer cells at concentration six times higher than those we used in our study ${ }^{35}$, whereas Pinus Sylvestris EO (EO29) exhibited some potential as an antiproliferative agent in the same cellular model (i.e., MDAMB-231 ${ }^{36}$, thus suggesting a different composition of EO used. In fact, we and other authors previously reported that multiple factors affect EO composition ${ }^{37-40}$.

A panel of melanoma cell lines, harboring wild type or mutant BRAF and NRAS, showed sensitivity to the six EOs, even if at a different extend, thus indicating that the effect of EOs was not related to BRAF or NRAS status.

All the six selected EOs, except for Pinus Sibirica (EO20), were investigated for their effect on cancer ${ }^{41-45}$ but only TTO (EO05) showed antitumor efficacy in preclinical 


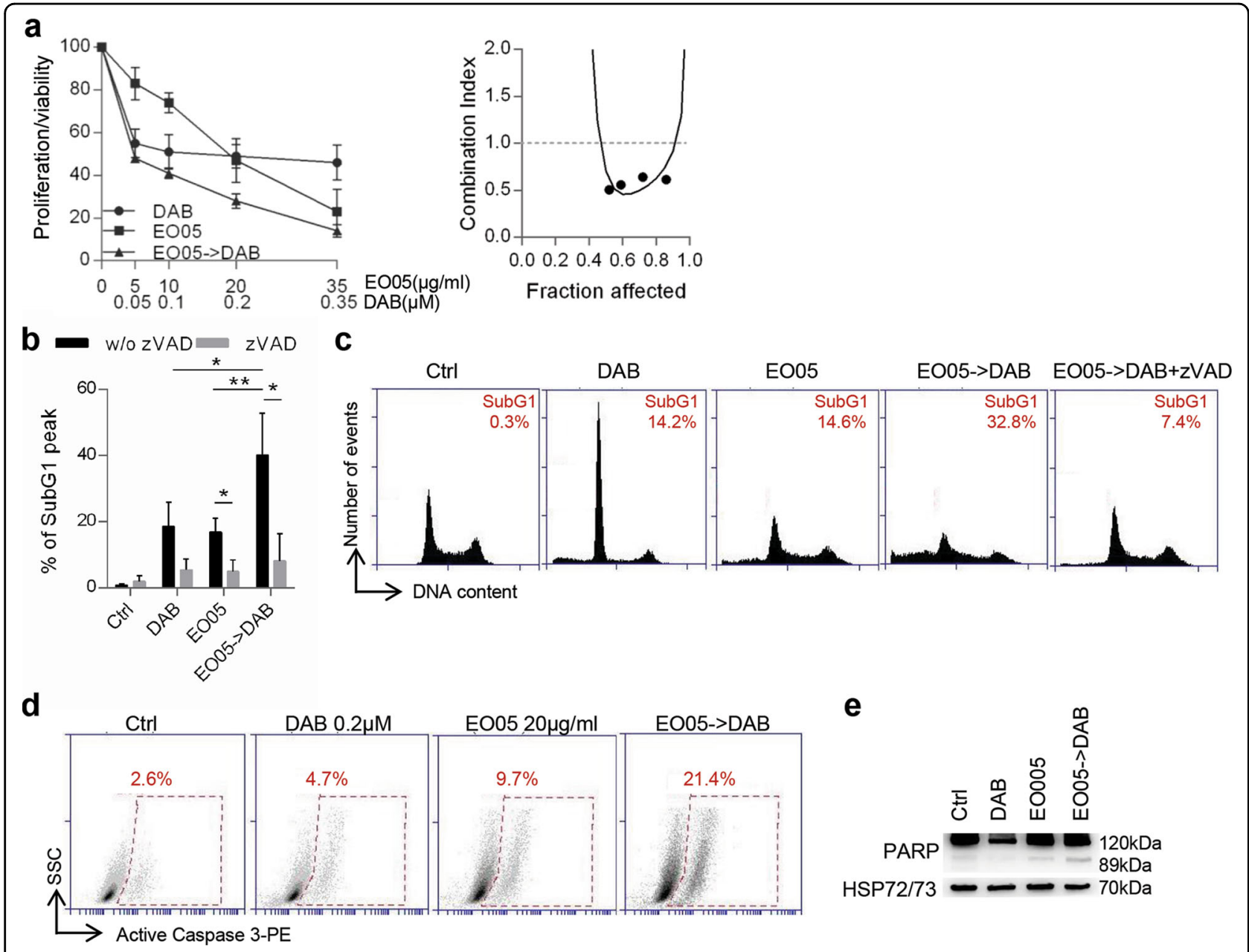

Fig. 3 EO05 sensitizes M14 melanoma cells to dabrafenib treatment. a Analysis of cell proliferation/viability by MTT assay (left) and relative isobologram (right) of M14 cells after treatment with dabrafenib (DAB) or EO05 alone or $24 \mathrm{~h}$ EO05 followed by $48 \mathrm{~h}$ dabrafenib (EO05-> DAB). The results are reported as "cell proliferation-viability of treated cells/cell proliferation-viability of control cells (Ctrl) $\times 100$ ". b Quantification and c representative images of subG1 peak by propidium iodide staining of M14 cells treated with DAB $(48 \mathrm{~h}, 0.2 \mu \mathrm{M}), \mathrm{EO} 05(24 \mathrm{~h}, 20 \mu \mathrm{g} / \mathrm{ml}) \mathrm{or}$ with $24 \mathrm{~h}$ EO05 followed by $48 \mathrm{~h}$ dabrafenib (EO05- > DAB) in the presence or absence of ZVAD (50 $\mu \mathrm{M})$. The percentage of cells in the subG1 peak is reported. $\mathbf{a}, \mathbf{b}$ The results represent the average \pm standard deviation of three independent experiments. Experiments with zVAD were repeated twice. b $p$-values were calculated between cells treated with combination and cells treated with single drugs, or between cells treated or not treated with zVAD. ${ }^{*} p<0.05 ;{ }^{*} p<0.01$ after applying Student's $t$ test. d Flow cytometric analysis of active caspase 3-PE staining in cells treated with DAB (48 h, $0.2 \mu \mathrm{M})$, EO05 $(24 \mathrm{~h}, 20 \mathrm{\mu g} / \mathrm{ml})$, or with $24 \mathrm{~h}$ EO05 followed by $48 \mathrm{~h}$ dabrafenib (EO05- > DAB). e Western Blot analysis of PARP cleavage in M14 cells treated as reported in $\mathbf{d}$. HSP72/73 was used as loading and transferring control. Western blot representative of two blots with similar results is shown.

melanoma models. In particular, through its most abundant component, terpinen-4-ol, TTO has been reported to reduce cell proliferation ${ }^{46-48}$, cause cell cycle perturbation ${ }^{47,48}$, induce necrosis ${ }^{47}$ or apoptosis ${ }^{46,48}$, and interfere with in vitro invasive/migratory capability ${ }^{49}$ of melanoma models. Moreover, a topical formulation of TTO retarded the in vivo growth of subcutaneous melanoma and evidenced immune effector cell recruitment on the treated region ${ }^{50}$. Considering all these effects, the EOs lipophilicity, the fact that EOs are well absorbed through the $\operatorname{skin}^{51}$, as well as the fact that chemoprevention is an essential approach for cancer control $^{52}$, TTO has been suggested as a possible chemopreventive candidate to be used in topical formulations against melanoma and other types of skin cancer ${ }^{48,53}$.

Despite the great interest in TTO reported in the last years $^{54,55}$, the contribution of TTO as a sensitizer of cancer, and in particular, of melanoma therapy ${ }^{56,57}$, is unknown. We demonstrated that TTO synergized with dabrafenib and trametinib, when administered either as single agents or in combination, in terms of apoptosis induction, when TTO treatment was followed by exposure to one of the two drugs. However, we cannot exclude 


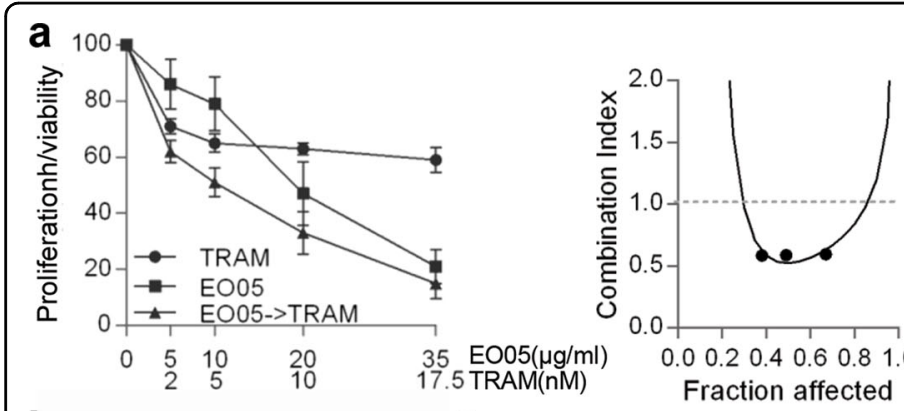

b w/ozVAD $\underset{* *}{\longrightarrow}$ ZVAD C
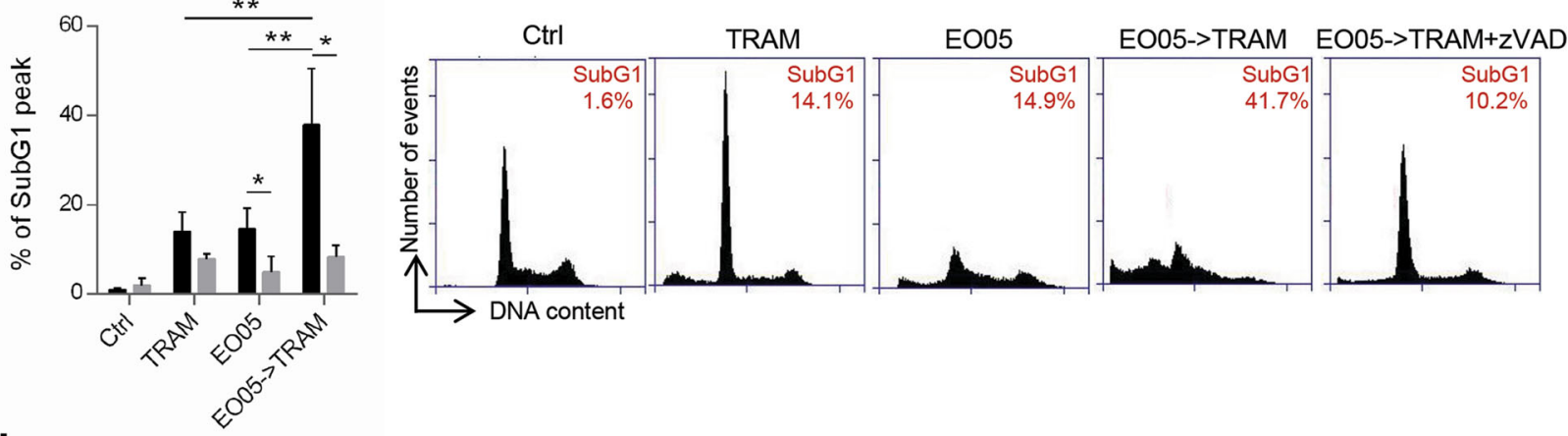

d

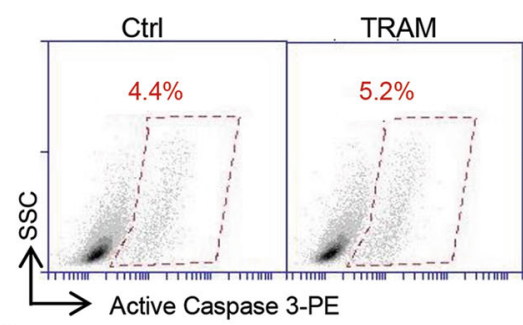

EO05
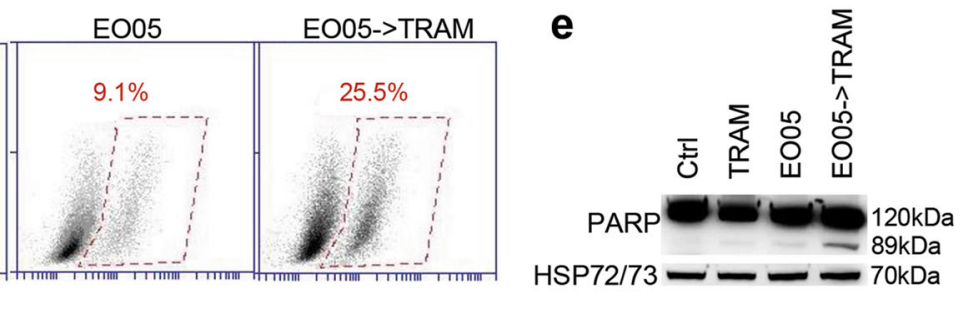

f

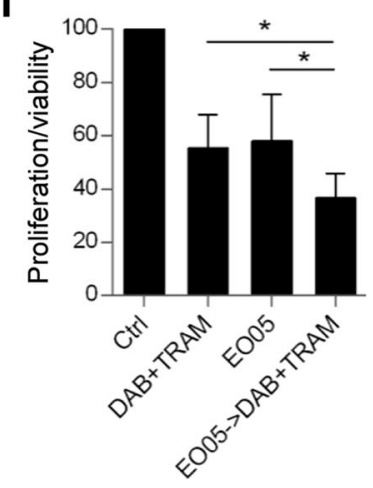

Fig. 4 EO05 sensitizes M14 melanoma cells to trametinib treatment. a Analysis of cell proliferation/viability by MTT assay (left) and relative isobologram (right) of M14 cells treated with $48 \mathrm{~h}$ trametinib (TRAM) or $24 \mathrm{~h}$ EO05 alone or $24 \mathrm{~h}$ EO05 followed by $48 \mathrm{~h}$ trametinib (EO05- > TRAM). b Quantification and $\mathbf{c}$ representative images relative of subG1 peak by propidium iodide staining of M14 cells control (Ctrl) or treated with TRAM $(48 \mathrm{~h}, 10 \mathrm{nM})$, EO05 $(24 \mathrm{~h}, 20 \mathrm{\mu g} / \mathrm{ml})$ or with $24 \mathrm{~h}$ EO05 followed by $48 \mathrm{~h}$ TRAM (EO05- > TRAM), in the presence or absence of zVAD $(50 \mu M)$. The percentage of cells in the subG1 peak is reported. $\mathbf{d}$ Flow cytometric analysis of active caspase 3-PE staining in cells treated with TRAM (48 h, $10 \mathrm{nM}$ ), EO05 $(24 \mathrm{~h}, 20 \mathrm{\mu g} / \mathrm{ml})$, or with $24 \mathrm{~h}$ EO05 followed by $48 \mathrm{~h}$ TRAM (EO05- > TRAM). e Western blot analysis of PARP cleavage in M14 cells treated as reported in $\mathbf{d}$. HSP72/73 was used as loading and transferring control. Western blot representative of two blots with similar results is shown. $\mathbf{f}$ MTT assay of M14 cells treated with dabrafenib $(0.001 \mu \mathrm{M})$ +trametinib $(0.1 \mathrm{nM})$ for $48 \mathrm{~h}, \mathrm{EO} 05(20 \mathrm{\mu g} / \mathrm{ml})$ for $24 \mathrm{~h}$ alone or $24 \mathrm{~h}$ EO05 followed by $48 \mathrm{~h}$ DAB + TRAM (EO05- > DAB + TRAM). $\mathbf{a}$, $\mathbf{f}$ The results are reported as "cell proliferation-viability of treated cells/cell proliferation-viability of control cells $\times 100^{\prime \prime} . \mathbf{a}, \mathbf{b}, \mathbf{f}$ The results represent the average \pm standard deviation of three independent experiments. Experiments with zVAD were repeated twice. $\mathbf{b}, \mathbf{f} p$-values were calculated between cells treated in combination and cells treated with single drugs, or between cells treated or not treated with zVAD. ${ }^{*} p<0.05 ;{ }^{* *} p<0.01$ after applying Student's $t$ test. 


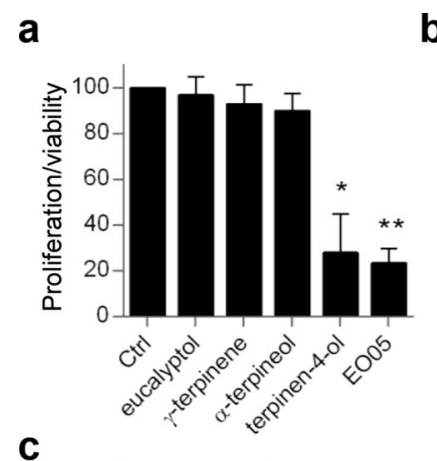

b

C
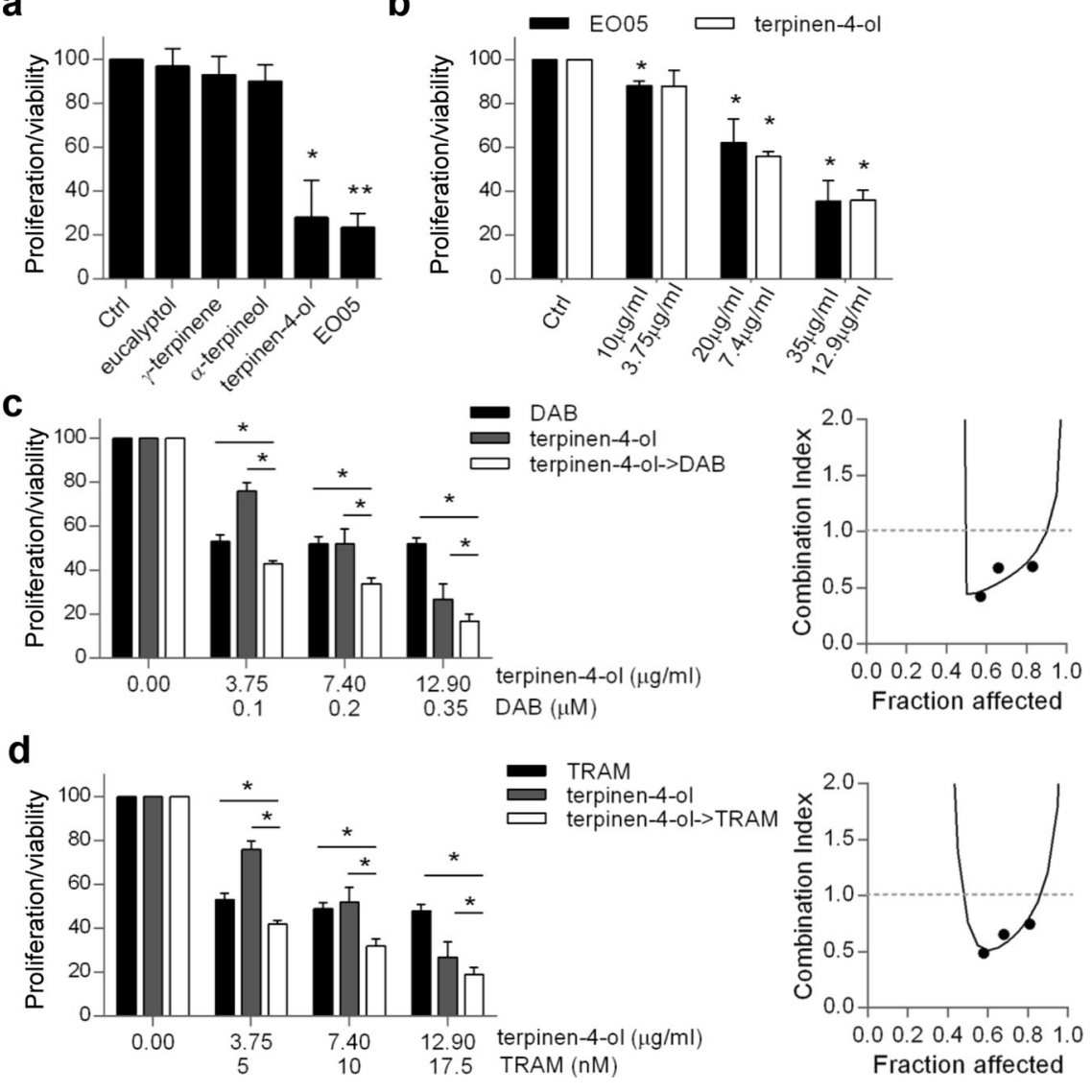

Fig. 5 Terpinen-4-ol is responsible for EO05 antitumor activity in M14 cells. a MTT assay of M14 cells treated for $72 \mathrm{~h}$ with eucalyptol $(7 \mu \mathrm{g} / \mathrm{ml})$, $\gamma$-terpinene $(6 \mu \mathrm{g} / \mathrm{ml})$, a-terpineol $(4 \mu \mathrm{g} / \mathrm{ml})$, terpinen-4-ol $(18.5 \mu \mathrm{g} / \mathrm{ml})$ or EO05 $(50 \mu \mathrm{g} / \mathrm{ml})$. b MTT assay of M14 cells treated with the indicated concentrations of EO05 or of terpinen-4-ol. c $\mathbf{d}$ MTT assay (left) and relative isobologram (right) of M14 cells treated with $\mathbf{c}$ dabrafenib (DAB), $\mathbf{d}$ trametinib (TRAM), or terpinen-4-ol alone or in combination ( $24 \mathrm{~h}$ terpinen-4-ol followed by $48 \mathrm{~h}$ DAB or TRAM). $\mathbf{a}-\mathbf{d}$ The results are reported as "cell proliferation-viability of treated cells/cell proliferation-viability of control cells $\times 100$ ". The results represent the average \pm standard deviation of at least three independent experiments. $p$-values were calculated between control (Ctrl) and treated cells or cells treated in combination and cells treated with single drugs. ${ }^{*} p<0.05 ;{ }^{* *} p<0.01$, after applying Student's $t$ test.

that TTO alone and in combination with targeted therapy may activate other forms of cell death.

In agreement with studies demonstrating that among TTO components, terpinen-4-ol is responsible of TTO efficacy $^{46,47,49}$, we demonstrated the relevance of terpinen-4-ol the main component present in TTO $(37.5 \%)$, in the antiproliferative effect and in the sensitization to target therapy. In mouse or human melanoma cells, TTO and terpinen-4-ol elicited G1 cell cycle arrest, showed an antiproliferative effect, antimigratory/antiinvasive ability against cells resistant to chemotherapy, and induced necrotic and apoptotic cell death ${ }^{46,47,49}$. We and other authors also reported terpinen-4-ol ability to affect in vitro and in vivo growth of tumors with different $\operatorname{origin}^{58-62}$, and to enhance the effect of several chemotherapeutic or biological agents in cancers not including melanoma ${ }^{61}$. Results from $\mathrm{ML}$ analysis performed on the M14 screening were in good agreement with experimental data effectively indicating terpinen-4-ol as one of the components mainly responsible for viability inhibition of melanoma cells. Indeed, among the final selected six EOs, EO05 did contain terpinen-4-ol at the highest percentage. The antiproliferative effect of EO12, EO18, EO20, EO29, and EO49, showing low or nondetectable levels of terpinen-4-ol could be due to other components present in their composition and reported to affect proliferation of melanoma cells, such as linalool ${ }^{63}$, limonene ${ }^{64}$, camphene ${ }^{65}, \alpha$-, and $\beta$-pinene ${ }^{66}$.

In agreement with studies demonstrating (i) the nature of terpenes as lipophilic molecules able to disrupt normal structure and function of cell membranes ${ }^{46}$, and (ii) the ability of TTO and terpinen-4-ol to interact with the lipid bilayer of cellular membranes and to inhibit the intracellular signaling induced by p170 glycoprotein $^{49,67}$, we 


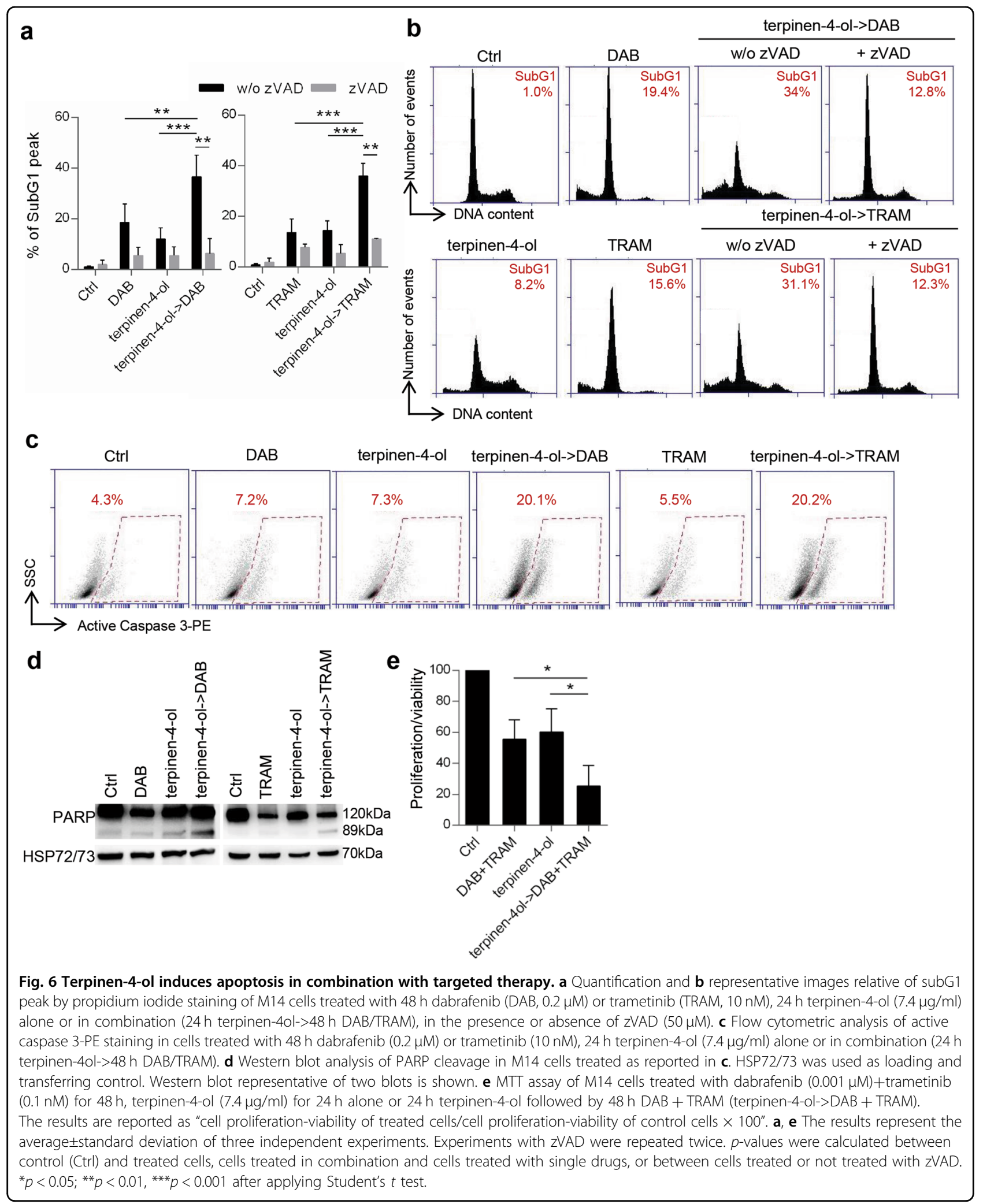


suggest that the synergistic effect of TTO or terpinen-4-ol with target therapy could be related to their effect on plasma membrane, i.e., reorganization of lipid architecture, thus favoring the entrance of drug in the cell.

Our data are in agreement with previous studies reporting the ability of EOs such as Cymbopogon citratus, or EO components, such as $\beta$-elemene and thymoquinone, to increase the efficacy of radiation in melanoma models ${ }^{68,69}$, or curcumol, $\beta$-caryophyllene, citral, or valencene to enhance the sensitivity of tumors from different origin to antineoplastic treatment ${ }^{70-72}$.

To the best of our knowledge, this is the first study examining the ability of TTO, and in particular, terpinen-4ol, to potentiate the targeted therapy of melanoma, highlighting the importance of our investigation. The efficacy of the combination TTO/target therapy could be of relevant importance as it can lead to the use of a lower concentration of drugs commonly used for the management of melanoma patients and consequently lower toxic treatments in terms of side-effect and more efficacious. The potential use of TTO is further supported by its non-toxicity in normal cells ${ }^{35}$ and by its penetrability in the $\operatorname{skin}^{73}$.

Supported by low toxicity and side-effect of EOs, as well as their good tolerance by patients, our study hold promise for further analysis of EOs as new anticancer drugs and/or as a source of potential anticancer supplement against melanoma. The effect of TTO on melanoma cells and the analysis of its main components are worthy of further investigation.

\section{Materials and methods Cell cultures}

Human melanoma (M14, A375, LOX IMVI, Sbcl1, ME4405, and ME1007) and lung cancer (H1299, A549) cell lines were cultured in Roswell Park Memorial Institute 1640 medium (Euroclone, Milan, IT). Colon cancer (HCT116), breast cancer (MDA-MB-231) cells, and human telomerase reverse transcriptase immortalized fibroblasts (BJ-hTERT) were cultured in Dulbecco's Modified Eagle's medium (Lonza, Basilea, $\mathrm{CH}$ ) supplemented with $10 \%$ inactivated bovine serum (Gibco, Thermo Fisher Scientific, MA, USA). ME4405 and ME1007 cell lines were established as reported ${ }^{74}$. Sbcl1 cell line was provided by Beppino G Giovannella ${ }^{75}$. All the other cell lines were purchased from American Type Culture Collection (Manassas, VA). Cells were routinely tested for mycoplasma contamination and were recently authenticated.

\section{Reagents preparation and treatment}

EOs (Farmalabor srl, Assago, IT), dabrafenib, trametinib (Selleckchem Chemicals, Houston, TX, USA) and zVAD (abcam, Cambridge, UK) were dissolved in dimethyl sulfoxide (DMSO, Sigma Aldrich, St. Louis, MO, USA) and further diluted in complete medium. Cells were treated up to $0.001 \%$ DMSO as vehicle control. Eucalyptol, $\gamma$-terpinene, $\alpha$-terpineol, and terpinen-4-ol were diluted in complete medium. Methanol (Sigma Aldrich) was used to dilute EOs for GC-MS analysis.

\section{Analysis of cell proliferation/viability}

In all, $3 \times 10^{3}$ cells/well were seeded in 96-well plates and treated for $24-72 \mathrm{~h}$. Cell proliferation/viability was evaluated by measuring 3-[4,5-dimethylthiazol-2-yl]-2,5diphenyltetrazolium bromide inner salt (MTT, Sigma Aldrich) dye absorbance as previously reported ${ }^{76}$. The concentration of drug that reduces $50 \%$ of cell viability $\left(\mathrm{IC}_{50}\right)$ and $\mathrm{CI}$ were analyzed by using median-effect method (Calcusyn software, Biosoft). CI values of $<1,=1$, and $>1$ indicate, respectively, synergistic, additive, and antagonistic effects.

\section{Western blot and flow cytometric analyses}

Western blot analyses were performed as previously reported $^{77}$ using primary antibodies directed to PARP (cod. 51-6639GR, BD Bioscience, San Jose, CA) or HSP72/73 (cod. D00175805, Calbiochem, Saint Diego, CA, USA,) as control of loading and transfer. Anti-mouse immunoglobulin G-horseradish peroxidase-conjugated antibody (cod. 1858413, Amersham Biosciences, Freiburg, Germany) was used as a secondary antibody.

Cell cycle distribution by propidium iodide staining was performed as previously described ${ }^{78}$. Caspase 3 activation was evaluated using an active caspase 3-PE antibody (cat. 559565, BD Bioscience, San Jose, CA), following the manufacturer's instructions. All the cytofluorimetric analyses were performed using BD Accuri ${ }^{\mathrm{TM}}$ C6 flow cytometer.

\section{GC-MS analysis}

GC-MS analyses were carried out using a Perkin Elmer Clarus $500 \mathrm{GC}$ equipped with a flame ionization detector and coupled with a Clarus 500 mass spectrometer. A Stabilwax capillary column (Restek, Bellefonte, PA, USA) was used with helium as carrier gas $(1.0 \mathrm{~mL} / \mathrm{min})$. GC oven temperature was kept at $60^{\circ} \mathrm{C}$ for $5 \mathrm{~min}$ and programmed to $220^{\circ} \mathrm{C}$ at a rate of $5^{\circ} \mathrm{C} / \mathrm{min}$, and kept constant at $220^{\circ} \mathrm{C}$ for $30 \mathrm{~min}$. Mass spectra were acquired over $40-500 \mathrm{amu}$ with ionizing electron energy $70 \mathrm{eV}$. In all, $1 \mu \mathrm{L}$ of the EO was diluted in $1 \mathrm{~mL}$ of methanol and $1 \mu \mathrm{L}$ of the solution was injected into the GC injector at $280^{\circ} \mathrm{C}$. The identification of compounds of EOs was performed by comparing mass spectra with those reported in Nist and Wiley libraries. Linear retention indices were calculated after injection of $\mathrm{C} 8-\mathrm{C} 30$ aliphatic hydrocarbons mixture under the same conditions described above and compared with available linear retention indices data in the literature. 


\section{ML binary classification}

All calculations were performed using the Python programming language (version 3.7, https://www.python.org/) by executing in-house code in the Jupyter Notebook platform, as previously reported ${ }^{79,80}$. For details see supplementary material and Table S9, 10.

\section{Statistics}

Unless otherwise indicated, at least three independent experiments have been performed. Six technical points for each experimental group were used for MTT assay. The data were expressed as mean \pm standard deviation or \pm standard error of the mean. For continuous variables, differences between two groups were analyzed with Student's $t$ test (unpaired, two-sided). One-way ANOVA test was used to analyze differences between the three groups. $P<0.05$ was considered statistically significant. All statistical tests and the estimation of variation between groups were performed with GraphPad Prism 6 (GraphPad Software, Inc., La Jolla, CA, USA). All data were included in the analyses. Based on the variation shown in our preliminary results, we determined the sample sizes by using power analysis.

\section{Acknowledgements}

This article is dedicated to the memory of our wonderful colleague, Marianna, who started this project performing the first screening of EOs before she passed away. The perfume of the oils in the laboratory reminds us of the lightness with which Marianna conducted the experiments and faced her illness. Marta Di Martile was supported by a FIRC-AIRC fellowship for Italy. We thank Dr. Adele Petricca for the preparation of the manuscript. The research leading to these results has received funding from AIRC under IG 2020 - ID. 24315 project - P.I. DDB; IRCCS Regina Elena National Cancer Institute P.I MDM-Ricerca Corrente 2018-2020; Sapienza University of Rome Ateneo Grant 2019- P.I. RR (prot. RM11916B8876093E) and Ateneo Grant 2018-P.I. RR (prot. RM118164361B425B).

\begin{abstract}
Author details
${ }^{1}$ Preclinical Models and New Therapeutic Agents Unit, IRCCS Regina Elena National Cancer Institute, Via Elio Chianesi 53, Rome, Italy. ${ }^{2}$ Rome Center for Molecular Design, Department of Drug Chemistry and Technology, Sapienza University, Piazzale Aldo Moro 5, Rome, Italy. ${ }^{3}$ Department of Chemistry and Technologies of Drugs, Sapienza University, Piazzale Aldo Moro 5, Rome, Italy
\end{abstract}

\section{Author contributions}

D.D.B., R.R., and M.D.M. performed study concept and design; M.D.M., E.V., and S.D. performed and analyzed in vitro experiments on tumor cell lines; R.R., M.S., S.G. performed development of methodology, analysis, and interpretation of data regarding EOs composition and M.L. studies; M.D.M. and D.D.B. drafted the article. All the authors revised the article critically, read and approved the final version of the manuscript.

\section{Data availability}

Data sets related to this article can be found at [https://gbox.garr.it/garrbox/ index.php/s/R8CXBDawomyk632].

\section{Conflict of interest}

The authors declare no competing interests.

\section{Publisher's note}

Springer Nature remains neutral with regard to jurisdictional claims in published maps and institutional affiliations.

Supplementary information The online version contains supplementary material available at https://doi.org/10.1038/s41420-021-00510-3.
Received: 10 March 2021 Revised: 22 April 2021 Accepted: 1 May 2021

Published online: 31 May 2021

\section{References}

1. Davies, $\mathrm{H}$. et al. Mutations of the BRAF gene in human cancer. Nature $\mathbf{4 1 7}$ 949-954 (2002).

2. Lu, H. et al. PAK signalling drives acquired drug resistance to MAPK inhibitors in BRAF-mutant melanomas. Nature 550, 133-136 (2017).

3. Yuan, R. et al. Natural products to prevent drug resistance in cancer chemotherapy: a review. Ann. N. Y. Acad. Sci. 1401, 19-27 (2017).

4. Flaherty, L. E. et al. Southwest Oncology Group S0008: a phase III trial of highdose interferon Alfa-2b versus cisplatin, vinblastine, and dacarbazine, plus interleukin-2 and interferon in patients with high-risk melanoma-an intergroup study of cancer and leukemia Group B, Children's Oncology Group, Eastern Cooperative Oncology Group, and Southwest Oncology Group. J. Clin. Oncol. 32, 3771-3778 (2014).

5. Mattila, K. E. et al. Combination chemotherapy with temozolomide, lomustine, vincristine and interferon-alpha (TOL-IFN) plus vemurafenib or TOL-IFN as firstline treatment for patients with advanced melanoma. Acta Oncol. 59, 310-314 (2020).

6. Qin, W. et al. Dissolving microneedles with spatiotemporally controlled pulsatile release nanosystem for synergistic chemo-photothermal therapy of melanoma. Theranostics 10, 8179-8196 (2020).

7. Munster, P. N. \& Daud, A. I. Preclinical and clinical activity of the topoisomerase I inhibitor, karenitecin, in melanoma. Expert Opin. Investig. Drugs 20, 1565-1574 (2011).

8. Alves-Silva, J. M., Zuzarte, M., Marques, C., Girão, H. \& Salgueiro, L. Protective effects of phenylpropanoids and phenylpropanoid-rich essential oils on the cardiovascular system. Mini Rev. Med. Chem. 19, 1459-1471 (2019).

9. Lari, Z. N. et al. Efficacy of inhaled Lavandula angustifolia Mill. Essential oil on sleep quality, quality of life and metabolic control in patients with diabetes mellitus type II and insomnia. J. Ethnopharmacol. 251, 112560 (2020).

10. Satheeshkumar, N., Vijayan, R. S., Lingesh, A., Santhikumar, S. \& Vishnuvardhan, C. Spices: potential therapeutics for Alzheimer's disease. Adv. Neurobiol. 12, 57-78 (2016).

11. Boukhatem, M. N. \& Setzer, W. N. Aromatic herbs, medicinal plant-derived essential oils, and phytochemical extracts as potential therapies for coronaviruses: future perspectives. Plants 9, 800 (2020).

12. Senthil Kumar, K. et al. Geranium and lemon essential oils and their active compounds downregulate angiotensin-converting enzyme 2 (ACE2), a SARSCoV-2 spike receptor-binding domain, in epithelial cells. Plants 9, 770 (2020).

13. Evans, A., Malvar, J., Garretson, C., Pedroja Kolovos, E. \& Baron Nelson, M. The use of aromatherapy to reduce chemotherapy-induced nausea in children with cancer: a randomized, double-blind, placebo-controlled trial. J. Pediatr. Oncol. Nurs. 35, 392-398 (2018).

14. Tamaki, K. et al. Randomized trial of aromatherapy versus conventional care for breast cancer patients during perioperative periods. Breast Cancer Res. Treat. 162, 523-531 (2017).

15. Ishfaq, P. M., Shukla, A., Beraiya, S., Tripathi, S. \& Mishra, S. K. Biochemical and pharmacological applications of essential oils in human health especially in cancer prevention. Anticancer Agents Med. Chem. 18, 1815-1827 (2018).

16. Lesgards, J. F., Baldovini, N., Vidal, N. \& Pietri, S. Anticancer activities of essential oils constituents and synergy with conventional therapies: a review. Phytother. Res. 28, 1423-1446 (2014).

17. Hakim, I. A., Harris, R. B. \& Ritenbaugh, C. Citrus peel use is associated with reduced risk of squamous cell carcinoma of the skin. Nutr. Cancer 37, 161-168 (2000).

18. da Fonseca, C. O. et al. Preliminary results from a phase $1 / / \mid$ study of perillyl alcohol intranasal administration in adults with recurrent malignant gliomas. Surg. Neurol. 70, 259-266 (2008)

19. Chen, T. C., Fonseca, C. O. \& Schönthal, A. H. Preclinical development and clinical use of perillyl alcohol for chemoprevention and cancer therapy. Am. J. Cancer Res. 5, 1580-1593 (2015).

20. Faria, G. M. et al. Intranasal perillyl alcohol therapy improves survival of patients with recurrent glioblastoma harboring mutant variant for MTHFR rs1801133 polymorphism. BMC Cancer 20, 1-10 (2020).

21. Sobral, M. V., Xavier, A. L., Lima, T. C. \& de Sousa, D. P. Antitumor activity of monoterpenes found in essential oils. ScientificWorldJournal 2014, 953451 (2014).

22. Pavithra, P. S., Mehta, A. \& Verma, R. S. Essential oils: from prevention to treatment of skin cancer. Drug Discov. Today 24, 644-655 (2019). 
23. Di Martile, M., Garzoli, S., Ragno, R. \& Bufalo, D. D. Essential oils and their main chemical components: the past 20 years of preclinical studies in melanoma. Cancers 12, 2650 (2020).

24. Carnesecchi, S. et al. Geraniol, a component of plant essential oils, modulates DNA synthesis and potentiates 5-fluorouracil efficacy on human colon tumor xenografts. Cancer Lett. 215, 53-59 (2004).

25. Polo, M. P., Crespo, R. \& de Bravo, M. G. Geraniol and simvastatin show a synergistic effect on a human hepatocarcinoma cell line. Cell Biochem Funct. 29, 452-458 (2011).

26. Li, L. J., Zhong, L. F., Jiang, L. P., Geng, C. Y. \& Zou, L. J. ß-Elemene radiosensitizes lung cancer A549 cells by enhancing DNA damage and inhibiting DNA repair. Phytother. Res, 25, 1095-1097 (2011).

27. Li, Q. Q. et al. beta-Elemene, a novel plant-derived antineoplastic agent, increases cisplatin chemosensitivity of lung tumor cells by triggering apoptosis. Oncol. Rep. 22, 161-170 (2009).

28. Legault, J. \& Pichette, A. Potentiating effect of $\beta$-caryophyllene on anticancer activity of a-humulene, isocaryophyllene and paclitaxel. J. Pharm. Pharm. 59, 1643-1647 (2007).

29. Rabi, T. \& Bishayee, A. d -Limonene sensitizes docetaxel-induced cytotoxicity in human prostate cancer cells: generation of reactive oxygen species and induction of apoptosis. J. Carcinog. 8, 9 (2009).

30. Hussain, A. et al. Eugenol enhances the chemotherapeutic potential of gemcitabine and induces anticarcinogenic and anti-inflammatory activity in human cervical cancer cells. Cancer Biother. Radiopharm. 26, 519-527 (2011).

31. Effenberger-Neidnicht, K. \& Schobert, R. Combinatorial effects of thymoquinone on the anti-cancer activity of doxorubicin. Cancer Chemother. Pharm. 67, 867-874 (2011).

32. Lei, $\mathbf{X}$. et al. Thymoquinone inhibits growth and augments 5-fluorouracilinduced apoptosis in gastric cancer cells both in vitro and in vivo. Biochem Biophys. Res. Commun. 417, 864-868 (2012).

33. Carson, C. F., Hammer, K. A. \& Riley, T. V. Melaleuca alternifolia (Tea Tree) oil: a review of antimicrobial and other medicinal properties. Clin. Microbiol. Rev. 19, 50-62 (2006).

34. Jenkins R. W., Fisher D. E. Treatment of advanced melanoma in 2020 and beyond. J. Invest. Dermatol. 141, 23-31 (2020).

35. Assmann, C. E. et al. Tea tree oil presents in vitro antitumor activity on breast cancer cells without cytotoxic effects on fibroblasts and on peripheral blood mononuclear cells. Biomed. Pharmacother. 103, 1253-1261 (2018).

36. Hoai, N. T., Duc, H. V., Thao do, T., Orav, A. \& Raal, A. Selectivity of Pinus sylvestris extract and essential oil to estrogen-insensitive breast cancer cells Pinus sylvestris against cancer cells. Pharmacogn. Mag. 11, S290-S295 (2015).

37. Kim D. Y., et al. Chemical composition, antioxidant and anti-melanogenic activities of essential oils from chrysanthemum boreale makino at different harvesting stages. Chem. Biodivers. 15, https://doi.org/10.1002/cbdv.201700506 (2018).

38. Russo, A. et al. Chemical composition and anticancer activity of essential oils of Mediterranean sage (Salvia officinalis L.) grown in different environmental conditions. Food Chem. Toxicol. 55, 42-47 (2013).

39. Garzoli, S. et al. Multidisciplinary approach to determine the optimal time and period for extracting the essential oil from Mentha suaveolens Ehrh. Molecules 20, 9640-9655 (2015).

40. Bozovic, M., Navarra, A., Garzoli, S., Pepi, F. \& Ragno, R. Esential oils extraction: a 24-hour steam distillation systematic methodology. Nat. Prod. Res. 31, 2387-2396 (2017).

41. Hata, T. et al. Induction of apoptosis by Citrus paradisi essential oil in human leukemic (HL-60) cells. Vivo 17, 553-559 (2003).

42. $\mathrm{Zu}, \mathrm{Y}$. et al. Activities of ten essential oils towards Propionibacterium acnes and PC-3, A-549 and MCF-7 cancer cells. Molecules 15, 3200-3210 (2010).

43. Tayarani-Najaran, Z. et al. Comparative studies of cytotoxic and apoptotic properties of different extracts and the essential oil of Lavandula angustifolia on malignant and normal cells. Nutr. Cancer 66, 424-434 (2014).

44. Zhao, Y. et al. In vitro and in vivo efficacy studies of lavender angustifolia essential oil and its active constituents on the proliferation of human prostate cancer. Integr. Cancer Ther. 16, 215-226 (2017).

45. Loizzo, M. et al. Antiproliferative effects of essential oils and their major constituents in human renal adenocarcinoma and amelanotic melanoma cells. Cell Prolif. 41, 1002-1012 (2008).

46. Calcabrini, A. et al. Terpinen-4-ol, the mai $n$ component of Melaleuca alternifolia (tea tree) oi I inhibits the in vitro growth of human melanom a cells. J. Invest. Dermatol. 122, 349-360 (2004).
47. Greay, S. J. et al. Induction of necrosis and cell cycle arrest in murine cancer cell lines by Melaleuca alternifolia (tea tree) oil and terpinen-4-ol. Cancer Chemother. Pharm. 65, 877-888 (2010).

48. Ramadan, M. A., Shawkey, A. E., Rabeh, M. A. \& Abdellatif, A. O. Expression of P53, $B A X$, and $B C L-2$ in human malignant melanoma and squamous cell carcinoma cells after tea tree oil treatment in vitro. Cytotechnology 71, 461-473 (2019).

49. Bozzuto, G., Colone, M., Toccacieli, L., Stringaro, A. \& Molinari, A. Tea tree oil might combat melanoma. Planta Med. 77, 54-56 (2011).

50. Greay, S. J. et al. Inhibition of established subcutaneous murine tumour growth with topical Melaleuca alternifolia (tea tree) oil. Cancer Chemother. Pharm. 66, 1095-1102 (2010).

51. Herman, A. \& Herman, A. P. Essential oils and their constituents as skin penetration enhancer for transdermal drug delivery: a review. J. Pharm. Pharm. 67, 473-485 (2015).

52. Sporn, M. B. \& Suh, N. Chemoprevention: an essential approach to controlling cancer. Nat. Rev. Cancer 2, 537-543 (2002).

53. Einspahr, J. G., Stratton, S. P., Bowden, G. T. \& Alberts, D. S. Chemoprevention of human skin cancer. Crit. Rev. Oncol. Hematol. 41, 269-285 (2002).

54. Pazyar, N., Yaghoobi, R., Bagherani, N. \& Kazerouni, A. A review of applications of tea tree oil in dermatology. Int J. Dermatol. 52, 784-790 (2013).

55. Hawkins, J., Hires, C., Dunne, E. \& Baker, C. The relationship between lavender and tea tree essential oils and pediatric endocrine disorders: a systematic review of the literature. Complement Ther. Med. 49, 102288 (2020).

56. Fujimura T., Kambayashi Y., Ohuchi K., Muto Y., Aiba S. Treatment of advanced melanoma: past, present and future. Life 10, 208 (2020).

57. Bai X., Flaherty K. T. Targeted and immunotherapies in BRAF mutant melanoma: where we stand and what to expect. Br. J. Dermatol. https://doi.org/ 10.1111/bjd.19394 (2020).

58. Banjerdpongchai, R. \& Khaw-On, P. Terpinen-4-ol induces autophagic and apoptotic cell death in human leukemic HL-60 cells. Asian Pac. J. Cancer Prev. 14, 7537-7542 (2013).

59. Laghezza Masci V., et al. Apoptotic effects on HL60 human leukaemia cells induced by lavandin essential oil treatment. Molecules 25, 538 (2020).

60. Nakayama, $\mathrm{K}$. et al. Terpinen-4-ol inhibits colorectal cancer growth via reactive oxygen species. Oncol. Lett. 14, 2015-2024 (2017).

61. Shapira, S., Pleban, S., Kazanov, D., Tirosh, P. \& Arber, N. Terpinen-4-ol: a novel and promising therapeutic agent for human gastrointestinal cancers. PloS ONE 11, e0156540 (2016)

62. Wu, C. S. et al. Terpinen-4-ol induces apoptosis in human nonsmall cell lung cancer in vitro and in vivo. Evid. Based Complement Altern. Med. 2012, 818261 (2012).

63. Cerchiara, T. et al. Antiproliferative effect of linalool on RPMI 7932 human melanoma cell line: ultrastructural studies. Nat. Prod. Commun. 10, 547-549 (2015).

64. Mitropoulou, G. et al. Citrus medica essential oil exhibits significant antimicrobial and antiproliferative activity. LWT 84, 344-352 (2017).

65. Girola, N. et al. Camphene isolated from essential oil of Piper cernuum (Piperaceae) induces intrinsic apoptosis in melanoma cells and displays antitumor activity in vivo. Biochem. Biophys. Res. Commun. 467, 928-934 (2015).

66. Santana, J. S. et al. Essential oils from Schinus terebinthifolius leaves-chemical composition and in vitro cytotoxicity evaluation. Pharm. Biol. 50, 1248-1253 (2012).

67. Giordani, C. et al. Interaction of tea tree oil with model and cellular membranes. J. Med. Chem. 49, 4581-4588 (2006).

68. Balavandi, Z . et al. The use of ß-elemene to enhance radio sensitization of A375 human melanoma cells. Cell J. 21, 419-425 (2020).

69. Hatiboglu, M. A. et al. Thymoquinone induces apoptosis in B16-F10 melanoma cell through inhibition of p-STAT3 and inhibits tumor growth in a murine intracerebral melanoma model. World Neurosurg. 114, e182-e190 (2018).

70. Ambrož M., et al. The effects of selected sesquiterpenes from myrica rubra essential oil on the efficacy of doxorubicin in sensitive and resistant cancer cell lines. Molecules 22, 1021 (2017).

71. Zeng, C. et al. Curcumol enhances the sensitivity of doxorubicin in triplenegative breast cancer via regulating the miR-181b-2-3p-ABCC3 axis. Biochem Pharm. 174, 113795 (2020).

72. Maruoka, T. et al. Lemongrass essential oil and citral inhibit Src/Stat3 activity and suppress the proliferation/survival of small-cell lung cancer cells, alone or in combination with chemotherapeutic agents. Int J. Oncol. 52, 1738-1748 (2018).

73. Cross, S. E., Russell, M., Southwell, I. \& Roberts, M. S. Human skin penetration of the major components of Australian tea tree oil applied in its pure form and as a $20 \%$ solution in vitro. Eur. J. Pharm. Biopharm. 69, 214-222 (2008).

74. D'Aguanno, S. et al. Semaphorin 5A drives melanoma progression: role of Bcl2, miR-204 and c-Myb. J. Exp. Clin. Cancer Res. 37, 278 (2018). 
75. Verschraegen, C. F., Mendoza, J. T., Kozielski, A. J. \& Giovanella, B. C. Modulation of the response to chemotherapy in a human melanoma clone by the site of growth in the nude mouse. Anticancer Res. 15, 9-11 (1995).

76. Di Martile, M. et al. Histone deacetylase inhibitor ITF2357 leads to apoptosis and enhances doxorubicin cytotoxicity in preclinical models of human sarcoma. Oncogenesis 7, 1-14 (2018).

77. Tupone, M. G. et al. microRNA-378a-5p is a novel positive regulator of melanoma progression. Oncogenesis 9, 1-13 (2020).
78. Del Bufalo, D. et al. Histone deacetylase inhibition synergistically enhances pemetrexed cytotoxicity through induction of apoptosis and autophagy in non-small cell lung cancer. Mol. Cancer 13, 230 (2014).

79. Papa R., et al. Essential oils biofilm modulation activity, chemical and machine learning analysis. application on staphylococcus aureus isolates from cystic fibrosis patients. Int. J. Mol. Sci. 21, 9258 (2020).

80. Patsilinakos A., et al. Machine learning analyses on data including essential oil chemical composition and in vitro experimental antibiofilm activities against staphylococcus species. Molecules 24, 890 (2019). 